Article

\title{
Optical and Piezoelectric Study of KNN Solid Solutions Co-Doped with La-Mn and Eu-Fe
}

\author{
Jesús-Alejandro Peña-Jiménez ${ }^{1}$, Federico González ${ }^{2}$, Rigoberto López-Juárez ${ }^{3}$, \\ José-Manuel Hernández-Alcántara ${ }^{4}$, Enrique Camarillo ${ }^{4}$, Héctor Murrieta-Sánchez ${ }^{4}$, \\ Lorena Pardo ${ }^{5}$ and María-Elena Villafuerte-Castrejón ${ }^{1,5, *}$ \\ 1 Instituto de Investigaciones en Materiales, Universidad Nacional Autónoma de México, \\ Ciudad Universitaria, A.P. 70-360, México D.F. 04510, Mexico; jesusalejandropea@gmail.com \\ 2 Departamento de Ingeniería de Procesos e Hidráulica, Universidad Autónoma Metropolitana-Iztapalapa, \\ A.P. 55-534, México D.F. 09340, Mexico; fgg@xanum.uam.mx \\ 3 Unidad Morelia del Instituto de Investigaciones en Materiales, Universidad Nacional Autónoma de México, \\ Antigua Carretera a Pátzcuaro No. 8701, Col. Ex Hacienda de San José de la Huerta, Morelia C.P. 58190, \\ Mexico; rlopez@iim.unam.mx \\ 4 Instituto de Física, Universidad Nacional Autónoma de México, A.P. 20-364, México D.F. 04510, Mexico; \\ josemh@fisica.unam.mx (J.-M.H.-A.); cgarcia@fisica.unam.mx (E.C.); murrieta@fisica.unam.mx (H.M.-S.) \\ 5 Instituto de Ciencia de Materiales de Madrid (ICMM), CSIC. c/ Sor Juana Inés de la Cruz, 3. Cantoblanco, \\ Madrid 28049, Spain; lpardo@icmm.csic.es \\ * Correspondence: mevc@unam.mx; Tel.: +52-55-5622-4646
}

Academic Editor: Beatriz Noheda

Received: 15 July 2016; Accepted: 22 September 2016; Published: 28 September 2016

\begin{abstract}
The solid-state method was used to synthesize single phase potassium-sodium niobate $(\mathrm{KNN})$ co-doped with the $\mathrm{La}^{3+}-\mathrm{Mn}^{4+}$ and $\mathrm{Eu}^{3+}-\mathrm{Fe}^{3+}$ ion pairs. Structural determination of all studied solid solutions was accomplished by XRD and Rietveld refinement method. Electron paramagnetic resonance (EPR) studies were performed to determine the oxidation state of paramagnetic centers. Optical spectroscopy measurements, excitation, emission and decay lifetime were carried out for each solid solution. The present study reveals that doping $\mathrm{KNN}$ with $\mathrm{La}^{3+}-\mathrm{Mn}^{4+}$ and $\mathrm{Eu}^{3+}-\mathrm{Fe}^{3+}$ at concentrations of $0.5 \mathrm{~mol} \%$ and $1 \mathrm{~mol} \%$, respectively, improves the ferroelectric and piezoelectric behavior and induce the generation of optical properties in the material for potential applications.
\end{abstract}

Keywords: perovskite; alkaline niobates; co-doping; lead-free ceramics; Rietveld method; EPR; optical activity; dielectric permittivity; ferroelectricity; piezoelectricity

\section{Introduction}

Lead-based piezoelectric ceramics, such as the lead titanate-zirconate (PZT) family, have played an important role for several decades because of their excellent piezoelectric and electromechanical properties [1]. However, due to the use of $\mathrm{PbO}$ during processing and its toxicity, the development of lead-free piezoceramics has become a worldwide research topic in materials [2-4]. Alkali niobate ceramics based on $\mathrm{K}_{0.5} \mathrm{Na}_{0.5} \mathrm{NbO}_{3}(\mathrm{KNN})$ have received more attention after Saito et al. [5] improved the piezoelectric coefficient $\mathrm{d}_{33}$ to $416 \mathrm{pC} / \mathrm{N}$ by doping with $\mathrm{Li}$, Ta and $\mathrm{Sb}$, making the perovskite more covalent and increasing the $<001>$ orientation.

The $\left(\mathrm{Na}_{1-\mathrm{x}} \mathrm{K}_{\mathrm{x}}\right) \mathrm{NbO}_{3}(\mathrm{KNN})$ is a solid solution formed between an antiferroelectric compound $\mathrm{NaNbO}_{3}$ and a ferroelectric compound $\mathrm{KNbO}_{3}$, whose phase diagram shows that, at room temperature, the orthorhombic phase becomes stable in the range of $0.475<\mathrm{x}<1$, and the monoclinic phase becomes stable in the range of $0.32<x<0.475$ [6-8]. In the KNN processing the main disadvantage is the volatility of sodium and potassium at temperatures above $850{ }^{\circ} \mathrm{C}$ used at synthesis and sintering steps [9]. 
It has been reported that addition of $\mathrm{Mn}_{2} \mathrm{O}_{3}$ or $\mathrm{MnO}_{2}$ could be used to reduce the leakage current in $\mathrm{KNN}$ ceramics, because they diminish the amount of oxygen vacancies formed due the volatilization of alkali ions by increasing the valence of $\mathrm{Mn}^{2+}$ or decreasing the valence of $\mathrm{Mn}^{4+}$ [10-12]. Besides, this selection of doping is promising as transparent glass ceramics showed optical properties ascribed to $\mathrm{Mn}^{2+}$ ions [13].

On the other hand, lead-free $((1-x) / 2) \mathrm{K}_{0.5} \mathrm{Na}_{0.5} \mathrm{Nb}_{0.95} \mathrm{Ta}_{0.05} \mathrm{O}_{3-\mathrm{x}} / 2 \mathrm{Fe}_{2} \mathrm{O}_{3}$ piezoelectric ceramics $(\mathrm{x}=0$, to $3.0 \mathrm{~mol} \%)$ have been prepared by conventional ceramic sintering process [14]. $\mathrm{K}^{+}$and $\mathrm{Na}^{+}$ vacancies, originating from the volatilization of alkali metal elements, and charge compensation by the diffused $\mathrm{Fe}^{3+}$ ions at low doping concentration ( $\left.0.4 \mathrm{~mol} \%\right)$ might be responsible for the higher tetragonal distortion of the structure and for inducing domain wall motions, which improves the electrical properties. $\mathrm{Fe}_{2} \mathrm{O}_{3}$ has been added also to enhance the piezoelectric properties in single crystals of ferroelectric potassium tantalate niobate $\left(\mathrm{KTa}_{\mathrm{x}} \mathrm{Nb}_{1-\mathrm{x}} \mathrm{O}_{3}\right)$ [15].

Previous reports have shown that, additionally to the improvement of the piezoelectric properties, luminescent response can be achieved by doping $\mathrm{KN}$ and $\mathrm{KNN}$ with rare-earths, such as $\mathrm{Pr}^{3+}, \mathrm{Er}^{3+}$ and $\mathrm{Eu}^{3+}$ [16-19]. Rare-earth doped materials have been of great scientific interest in developing photonic devices and for the next flat-panel display generation. $\mathrm{Eu}^{3+}$-doped materials have been extensively studied because of their transitions from ${ }^{5} \mathrm{D}_{0}$ to ${ }^{7} \mathrm{~F}_{\mathrm{J}}(\mathrm{J}=0,1,2,3,4)$ levels. Mainly, the transition ${ }^{5} \mathrm{D}_{0}$ to ${ }^{7} \mathrm{~F}_{2}$, involved in wavelength peaks around $610-630 \mathrm{~nm}$, shows bright red luminescence and laser action in a variety of glasses and single crystals [16-18].

Being a ferroelectric with perovskite structure KNN ceramics have been widely studied as the host material for photoluminescence application in nonlinear optics. The doping is of great importance in modifying the crystallographic phase and tuning photoluminescence properties in the invisible-near infrared range [16-18]. Although not yet studied, it is possible that co-doped KN and KNN could exhibit simultaneously piezoelectric and luminescent properties. The works on simultaneous characterization of the electrical (ferro- or piezo-electric) and optical properties in the search for multifunctional materials are scarce to date but slowly increased in the last few years [20-22]. Besides, co-doping for this dual purpose has not yet been studied.

This work reports the synthesis of $\mathrm{KNN}$ and its solid solutions substituting $\mathrm{Na}^{+}$and $\mathrm{K}^{+}$ in the A site of perovskite structure with $\mathrm{La}^{3+}$ and $\mathrm{Eu}^{3+}$, and $\mathrm{Nb}^{5+}$ in the $\mathrm{B}$ site with $\mathrm{Mn}^{4+}$ and $\mathrm{Fe}^{3+}$. The co-doped studied materials were prepared according with the formulations of $\left.\left(\left(\mathrm{K}_{0.5} \mathrm{Na}_{0.5}\right)_{(1-(4 \mathrm{x} / 5)}\right) \mathrm{La}_{(4 \mathrm{x} / 5)}\right)\left(\mathrm{Nb}_{(1-(4.5 \mathrm{x} / 5))} \mathrm{Mn}_{(4.5 \mathrm{x} / 5)}\right) \mathrm{O}_{3}$ and $\left(\left(\mathrm{K}_{0.5} \mathrm{Na}_{0.5}\right)_{1-\mathrm{x}} \mathrm{Eu}_{\mathrm{x}}\right)\left(\mathrm{Nb}_{1-\mathrm{x}} \mathrm{Fe}_{\mathrm{x}}\right) \mathrm{O}_{3}$, with $x=0.005$ and $x=0.01$. The purpose of using ions in those pairs was to maintain the charge balance and to establish the co-dopant effect avoiding redox process induced by vacancies generation. Furthermore, transition metals were added with the aim to enhance the ferroelectric, piezoelectric and dielectric properties [12,14,23], meanwhile both $\mathrm{Mn}$ and rare earths cations are expected to arise optical activity and $\mathrm{La}$ is expected to minimize the manganese reduction [10-12].

\section{Results and Discussion}

\subsection{Structural Characterization}

In order to facilitate data handling, the chemical formulas of the studied compounds are named as follows:

$$
\begin{aligned}
& \left(\mathrm{K}_{0.5} \mathrm{Na}_{0.5}\right) \mathrm{NbO}_{3}(\mathrm{KNN}) \\
& \left(\mathrm{K}_{0.5} \mathrm{Na}_{0.5}\right)_{0.995} \mathrm{La}_{0.004} \mathrm{Nb}_{0.995} \mathrm{Mn}_{0.0045} \mathrm{O}_{3} \text { (KNNLM05) } \\
& \left(\mathrm{K}_{0.5} \mathrm{Na}_{0.5}\right)_{0.992} \mathrm{La}_{0.008} \mathrm{Nb}_{0.990} \mathrm{Mn}_{0.0090} \mathrm{O}_{3} \text { (KNNLM1) } \\
& \left(\mathrm{K}_{0.5} \mathrm{Na}_{0.5}\right)_{0.995} \mathrm{Eu}_{0.005} \mathrm{Nb}_{0.995} \mathrm{Fe}_{0.005} \mathrm{O}_{3} \text { (KNNEF05) } \\
& \left(\mathrm{K}_{0.5} \mathrm{Na}_{0.5}\right)_{0.990} \mathrm{Eu}_{0.010} \mathrm{Nb}_{0.990} \mathrm{Fe}_{0.010} \mathrm{O}_{3} \text { (KNNEF1) }
\end{aligned}
$$

Figure 1 shows X-ray diffraction patterns and the calculated plots corresponding to the Rietveld refinement of the studied compounds. All of them show single crystalline phase indicating the 
solubility of the dopants into the KNN crystal structure (JCPDS No 00-061-0315), with evolution from the orthorhombic symmetry, described by Malic et al. [24], as the co-doping increase. The studied compositions were selected after a separate study, not shown here, to ensure that they constitute solid solutions. The solubility limit in KNNLM and KNNEF was determined to correspond to $\mathrm{x}=0.054$ for KNNLM and $\mathrm{x}=0.056$ for KNNEF samples. The obtained data from Rietveld analysis are listed in Table 1.
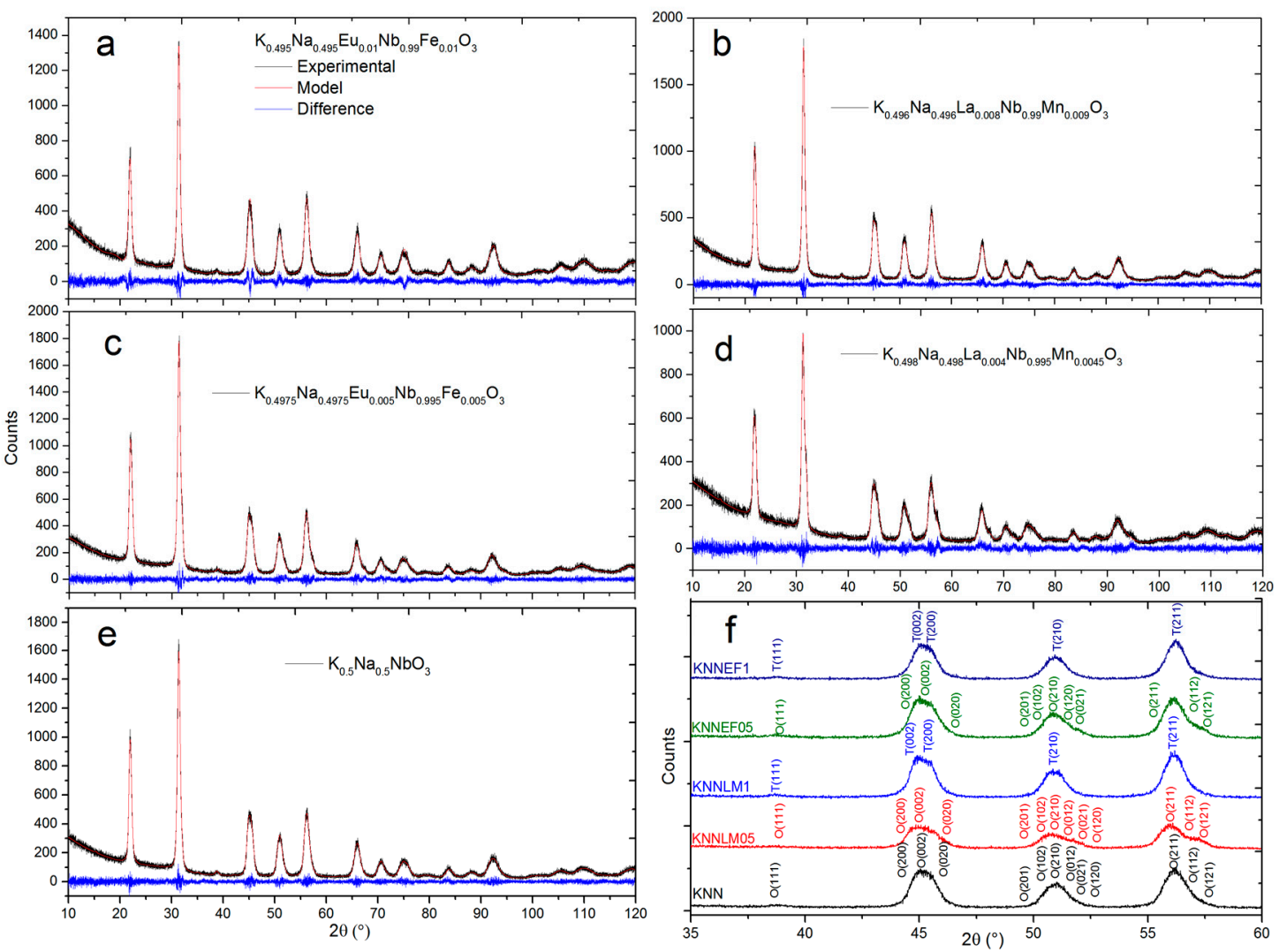

Figure 1. Experimental XRD patterns and results of their Rietveld refinement. (a) $\left(\mathrm{K}_{0.5} \mathrm{Na}_{0.5}\right)_{0.990} \mathrm{Eu}_{0.010}$ $\mathrm{Nb}_{0.990} \mathrm{Fe}_{0.010} \mathrm{O}_{3} ;$ (b) $\left(\mathrm{K}_{0.5} \mathrm{Na}_{0.5}\right)_{0.992} \mathrm{La}_{0.008} \mathrm{Nb}_{0.990} \mathrm{Mn}_{0.0090} \mathrm{O}_{3} ;$ (c) $\left(\mathrm{K}_{0.5} \mathrm{Na}_{0.5}\right)_{0.995} \mathrm{Eu}_{0.005} \mathrm{Nb}_{0.995} \mathrm{Fe}_{0.005} \mathrm{O}_{3}$; (d) $\left(\mathrm{K}_{0.5} \mathrm{Na}_{0.5}\right)_{0.995} \mathrm{La}_{0.004} \mathrm{Nb}_{0.995} \mathrm{Mn}_{0.0045} \mathrm{O}_{3} ;(\mathbf{e})\left(\mathrm{K}_{0.5} \mathrm{Na}_{0.5}\right) \mathrm{NbO}_{3} ;$ (f) comparison of some relevant peaks.

Table 1. Crystallographic parameters obtained from Rietveld refinement analysis for all solid solutions.

\begin{tabular}{cccccc}
\hline Composition & KNN & KNNLM05 & KNNLM1 & KNNEF05 & KNNEF1 \\
\hline $\mathrm{R}_{\mathrm{WP}} \%$ & 10.03 & 11.07 & 10.09 & 9.76 & 11.04 \\
$\mathrm{a}(\AA)$ & $4.005^{\mathrm{a}}$ & $3.101(6)$ & $3.964(2)$ & $3.261(4)$ & $3.976(2)$ \\
$\mathrm{b}(\AA)$ & $3.944^{\mathrm{a}}$ & $3.601(2)$ & $3.964(3)$ & $3.317(4)$ & $3.976(2)$ \\
$\mathrm{c}(\AA)$ & $4.002^{\mathrm{a}}$ & $4.005(6)$ & $3.989(2)$ & $4.005(4)$ & $3.981(3)$ \\
Crystal system & ortho & ortho & tetragonal & ortho & tetragonal \\
Space group & Amm2 & Amm2 & P4mm & Amm2 & P4mm \\
Volume $\left(\AA^{3}\right)$ & $127(2)$ & $121(1)$ & $122(1)$ & $122(1)$ & $124(1)$ \\
Average crystallite size $(\mathrm{nm})$ & $37(3)$ & $54(4)$ & $8(3)$ & $39(3)$ & $30(2)$ \\
Calculated density $\left(\mathrm{g} / \mathrm{cm}^{3}\right)$ & 4.578 & $4.495(6)$ & $4.528(3)$ & $4.543(4)$ & $4.568(4)$ \\
\hline
\end{tabular}

${ }^{a}$ Value taken from the reference [24].

Table 1 shows the percentage of weighted profile $R$-factor $\left(R_{w p}\right)$, which is the figure of merit commonly used in Rietveld refinement, the crystal cell parameters, average crystal size and density of the samples. The comparison of the estimated crystal cell parameters and density for all samples with the data available in the literature for pure KNN revealed that these parameters are in accordance 
with those ones previously reported [24]. It is worth noting the changes in crystal parameters, which result in a change of crystal symmetry, from orthorhombic [25] to tetragonal (see the comparison of some relevant peaks enlarged in Figure 1) and finally a mixture of symmetries as the amount of co-doping increases.

SEM images of the higher density samples, sintered at different temperatures are shown in Figure 2. The main feature observed is the change in crystal size, which can be ascribed to the dopant i.e., its presence influences the inhibition of growth rates by changing the defect concentration and therefore the mass diffusivity at the grain surface [26].

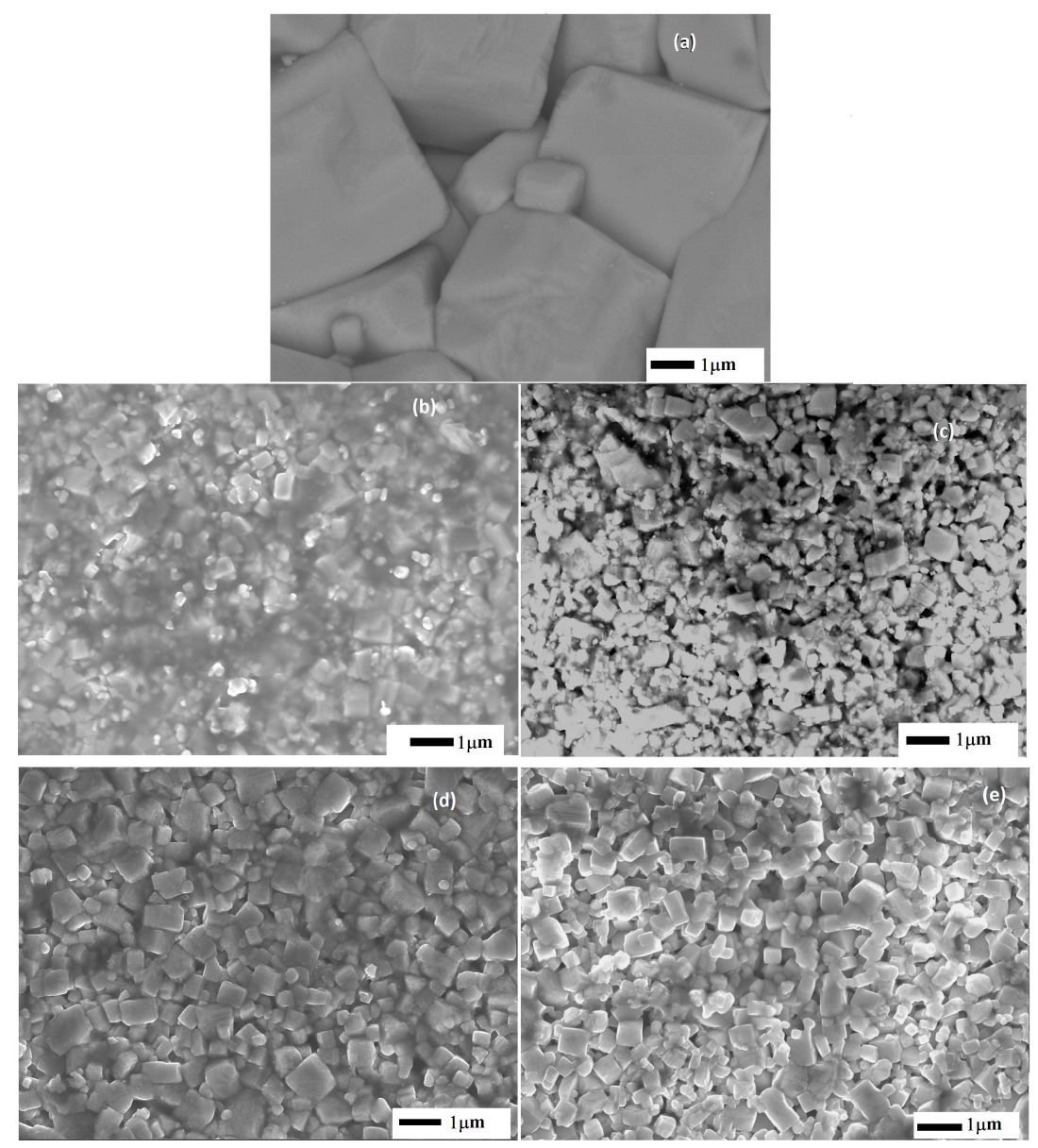

Figure 2. SEM images of sintered compounds (a) $\mathrm{KNN} \mathrm{T}=1105{ }^{\circ} \mathrm{C}$; (b) $\mathrm{KNNLM05} \mathrm{T}=1155{ }^{\circ} \mathrm{C}$; (c) $\mathrm{KNNLM} 1 \mathrm{~T}=1155^{\circ} \mathrm{C}$; (d) KNNEF05 $\mathrm{T}=1150{ }^{\circ} \mathrm{C}$ and $(\mathbf{e}) \mathrm{KNNEF1} \mathrm{T}=1135^{\circ} \mathrm{C}$.

Densification for sintered pellets is presented in Table 2, which were determined by comparing the calculated values from Rietveld refinement given in Table 1 and the measured by Arquimedes method.

Table 2. Theoretical and experimental density and densification percentage for sintered compounds.

\begin{tabular}{cccc}
\hline Compound & Calculated Density $\left(\mathbf{g} / \mathbf{c m}^{\mathbf{3}}\right)$ & Experimental Density $\mathbf{( g / \mathbf { c m } ^ { 3 } )}$ & Densification $\mathbf{( \% )}$ \\
\hline KNN & 4.578 & 4.329 & 94.6 \\
KNNLM05 & $4.495(6)$ & 4.399 & 97.9 \\
KNNLM1 & $4.528(3)$ & 4.266 & 94.2 \\
KNNEF05 & $4.543(4)$ & 4.378 & 96.4 \\
KNNEF1 & $4.568(4)$ & 4.419 & 96.7 \\
\hline
\end{tabular}


In Table 2 the lower densification value was obtained for KNNLM1 sample, most probably due to structural defects associated with the difference in ionic size and oxidation state of the $\mathrm{La}^{3+}$ with respect to $\mathrm{K}^{+}$and $\mathrm{Na}^{+}$and $\mathrm{Mn}^{2+} / \mathrm{Mn}^{4+}$ with respect to $\mathrm{Nb}^{5+}$. In order to get insight on the defect structure and valence state of the dopants in the studied compounds both EPR and luminescence studies were carried out.

\subsection{EPR and Optical Analysis}

EPR spectra are shown in Figure 3. The EPR technique is commonly used to determine the oxidation level of paramagnetic centers present in the compounds. The spectra of KNNLM05 (Figure 3a) and KNNLM1 (Figure 3b) exhibit classic $\mathrm{Mn}^{2+}$ transitions around $330 \mathrm{mT}$, which correspond to a ground state ${ }^{6} S_{5 / 2}$ with a spin value equal to $S=5 / 2$. The difference between these two spectra is detailed as follows [27]. In Figure 3a, the spectrum is split in six lines due to the hyperfine interaction with the ${ }^{55} \mathrm{Mn}$ nucleus [27-32]. In Figure $3 \mathrm{~b}$ the spectrum shows only one broad signal, this response is related with the dipole-dipole interaction induced by the dopant concentration. This response is consistent with the presence of $\mathrm{Mn}^{2+}$ ion, which, at lower symmetries, could present the fine structure transition between the ligand field split in levels, corresponding to $5 / 2-3 / 2,3 / 2-1 / 2,1 / 2--1 / 2$, $-1 / 2--3 / 2$ and $-3 / 2--5 / 2$ transitions [28]. Besides, at lower symmetries of $\mathrm{Mn}^{4+}$ the fine structure is split in levels corresponding to $3 / 2-1 / 2,1 / 2--1 / 2$ and $-1 / 2--3 / 2$. However, as a result of large anisotropy only a central signal with its six hyperfine components due to $\mathrm{Mn}^{2+}$ was observed and this signal can be overlapped by the response of $\mathrm{Mn}^{4+}$, being more sensitive for $\mathrm{Mn}^{2+}$ [27-35].

Meanwhile, the spectrum for KNNEF05, given in Figure 3c, exhibits two transitions. The first one, with a small intensity at $154 \mathrm{mT}$ might be assigned to $\mathrm{Fe}^{3+}$ by the 5/2-3/2 transition [36-38]. The second one at $330 \mathrm{mT}$, is more intense and corresponds to the $\mathrm{Fe}^{3+}$ ground state ${ }^{6} \mathrm{~S}_{5 / 2}$ due to the $1 / 2--1 / 2$ transition. Finally, the KNNEF1 compound (Figure 3d) shows two transitions: the first one at $330 \mathrm{mT}$ and the second at $400 \mathrm{mT}$; these two signals could also be attributed to $\mathrm{Fe}^{3+}$. The particular shape of the spectrum may be due to a significantly distortion of the crystal environment around $\mathrm{Fe}^{3+}$ induced by the higher concentration of the dopant for this sample.
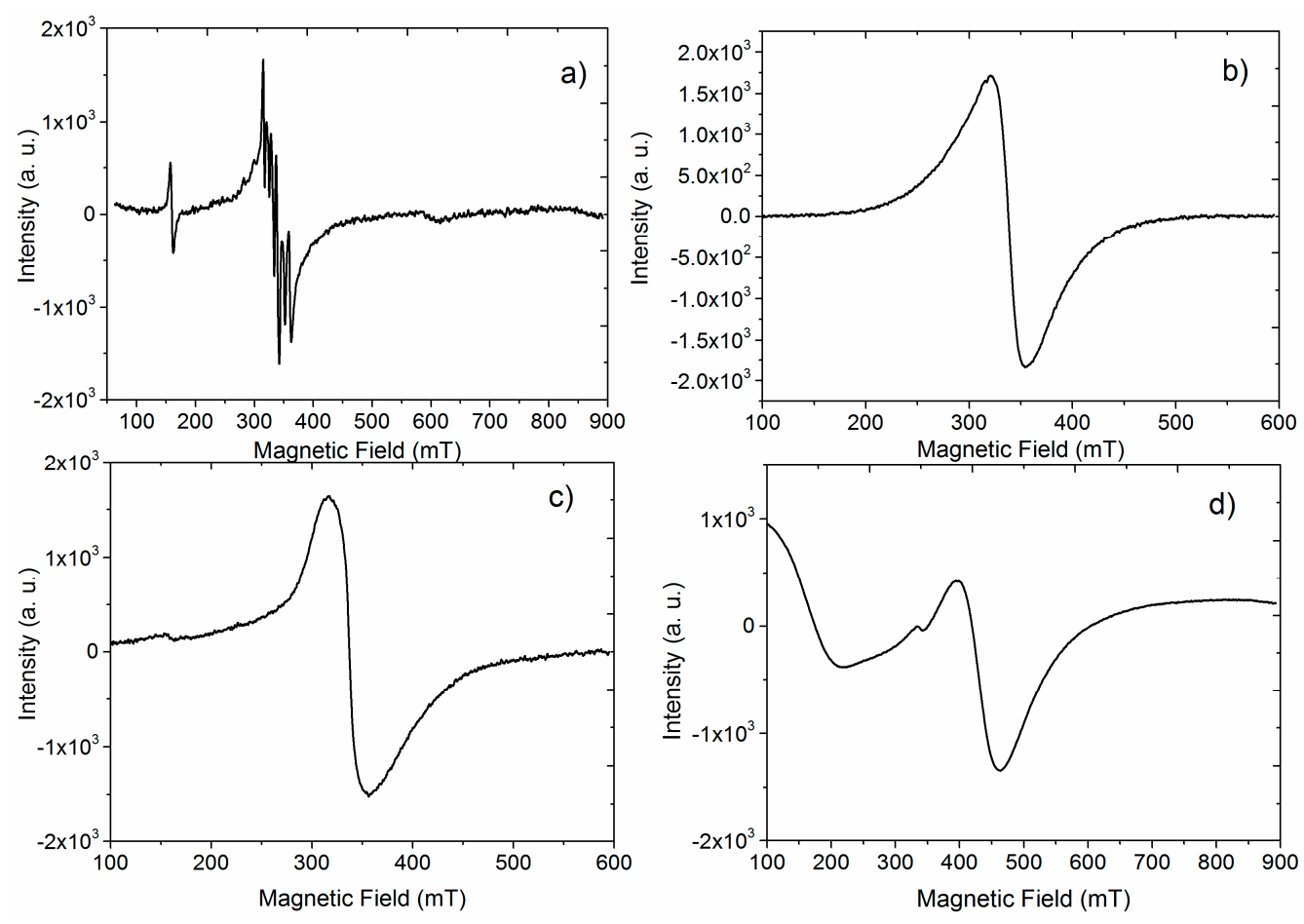

Figure 3. EPR spectra: (a) KNNLM05; (b) KNNLM1; (c) KNNEF05 and (d) KNNEF1. 
Luminescence excitation spectra are shown in Figure 4. The spectra of the solid solution co-doped with La-Mn (Figure 4a) exhibit a characteristic $\mathrm{Mn}^{4+}$ transition from ${ }^{4} \mathrm{~A}_{2}-{ }^{4} \mathrm{~T}_{2}$ at $410 \mathrm{~nm}$ [39]. Whereas those of the compounds co-doped with $\mathrm{Eu}-\mathrm{Fe}$, (Figure 4b) exhibit several transitions: characteristic of $\mathrm{f}-\mathrm{f}$ transitions of $\mathrm{Eu}^{3+}$, such as ${ }^{7} \mathrm{~F}_{0}-{ }^{5} \mathrm{D}_{4},{ }^{7} \mathrm{~F}_{0}-{ }^{5} \mathrm{G}_{6},{ }^{7} \mathrm{~F}_{0}-{ }^{5} \mathrm{~L}_{6},{ }^{7} \mathrm{~F}_{0}-{ }^{5} \mathrm{D}_{3},{ }^{7} \mathrm{~F}_{0}-{ }^{5} \mathrm{D}_{2}$ and ${ }^{7} \mathrm{~F}_{0}-{ }^{5} \mathrm{D}_{1}[16,18]$ that are observed at $360 \mathrm{~nm}, 380 \mathrm{~nm}, 395 \mathrm{~nm}, 417 \mathrm{~nm}, 466 \mathrm{~nm}$ and $528 \mathrm{~nm}$, respectively.
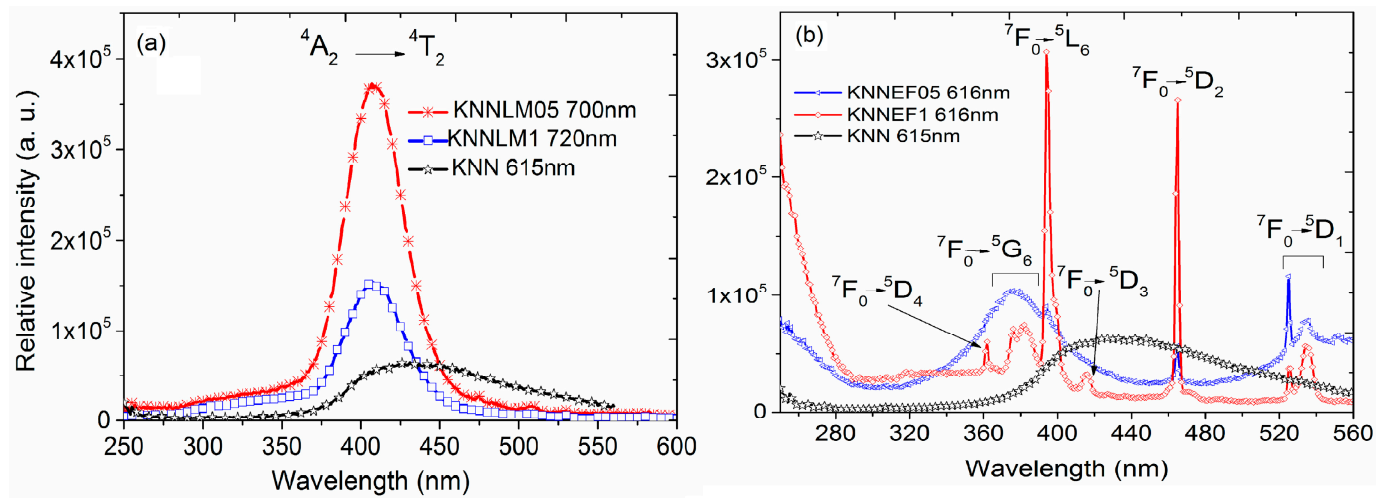

Figure 4. Excitation spectra of the (a) La-Mn co-doped KNN compounds and (b) Eu-Fe co-doped samples.

The emission spectra are presented in Figure 5. The spectra of the La-Mn co-doped compounds, (Figure 5a), exhibit a wide band centered at $720 \mathrm{~nm}$, which may be ascribed to the ${ }^{2} \mathrm{E}-{ }^{4} \mathrm{~A}_{2}$ transition of $\mathrm{Mn}^{4+}$ [39]. The emission spectra of solid solutions with Eu-Fe, (Figure 5b), show several transitions ascribed to Eu ${ }^{3+} \mathrm{f}-\mathrm{f}$ transition ${ }^{5} \mathrm{D}_{0}-{ }^{7} \mathrm{~F}_{0},{ }^{5} \mathrm{D}_{0}-{ }^{7} \mathrm{~F}_{1},{ }^{5} \mathrm{D}_{0}-{ }^{7} \mathrm{~F}_{2},{ }^{5} \mathrm{D}_{0}-{ }^{7} \mathrm{~F}_{3}$ and ${ }^{5} \mathrm{D}_{0}-{ }^{7} \mathrm{~F}_{4}[16,18]$.
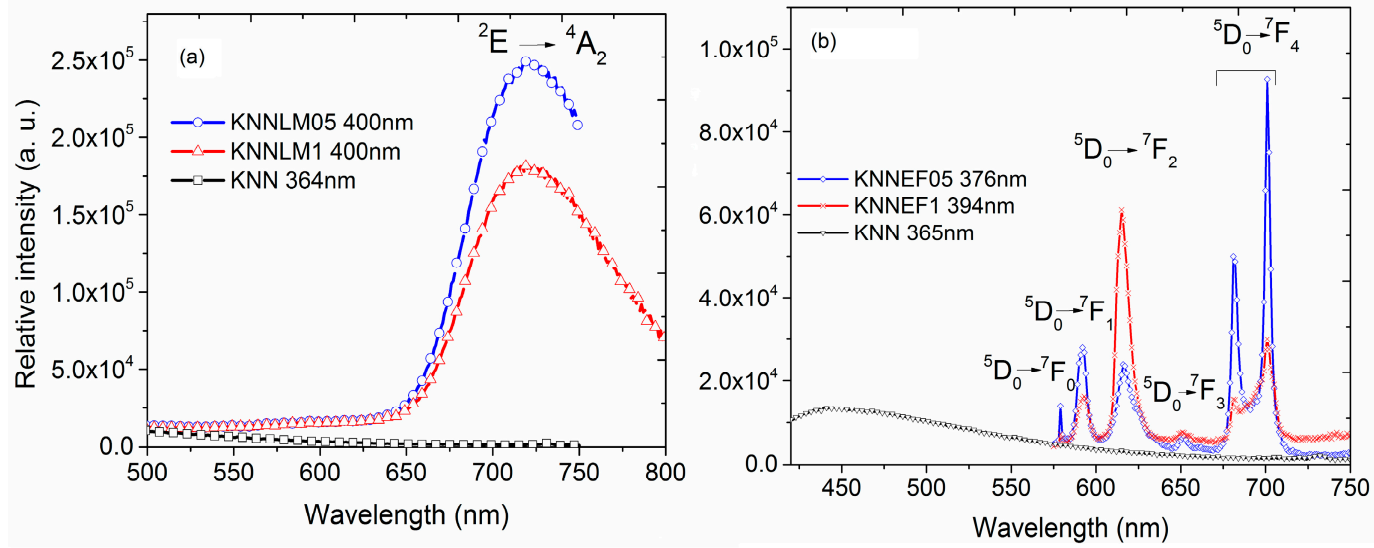

Figure 5. Emission spectra of (a) La-Mn co-doped KNN and (b) Eu-Fe solid solutions.

It should be noticed that $\mathrm{Eu}-\mathrm{Fe}$ co-doped samples experiment a change in the concentration-dependent relative intensity of the ${ }^{5} \mathrm{D}_{0}-{ }^{7} \mathrm{~F}_{1}$ and ${ }^{5} \mathrm{D}_{0}-{ }^{7} \mathrm{~F}_{2}$ transitions. The relative intensity $\mathrm{I}\left({ }^{7} \mathrm{~F}_{2}\right) / \mathrm{I}\left({ }^{7} \mathrm{~F}_{1}\right)$ of samples co-doped at $0.5 \%$ and $1 \%$ change from 0.86 to 3.77 . This result is an evidence of a higher distortion in the crystal structure at the local level due to a higher dopant content, which explains the improvement of dielectric, ferroelectric and piezoelectric properties of the $\mathrm{Eu}-\mathrm{Fe}$ co-doped compounds. Furthermore, this distortion correlates well with the $\mathrm{Fe}^{3+}$ environment showed from the EPR spectrum of sample KNNEF1.

The luminescent decay curves for the co-doped samples are depicted in Figure 6. They all have features of a complex de-excitation dynamic, i.e., they show a non-exponential decay behavior [40]. This fact is expected because the optically active ions $\mathrm{Mn}^{4+} / \mathrm{Eu}^{3+}$ are settled into the perovskite 
structure at sites of $\mathrm{K}^{+}$and $\mathrm{Na}^{+}$(A-site) and $\mathrm{Nb}^{5+}$ (B-site), respectively, inducing the crystal structure distortion, and generating defects, which may be responsible for the implied dynamic de-excitation.

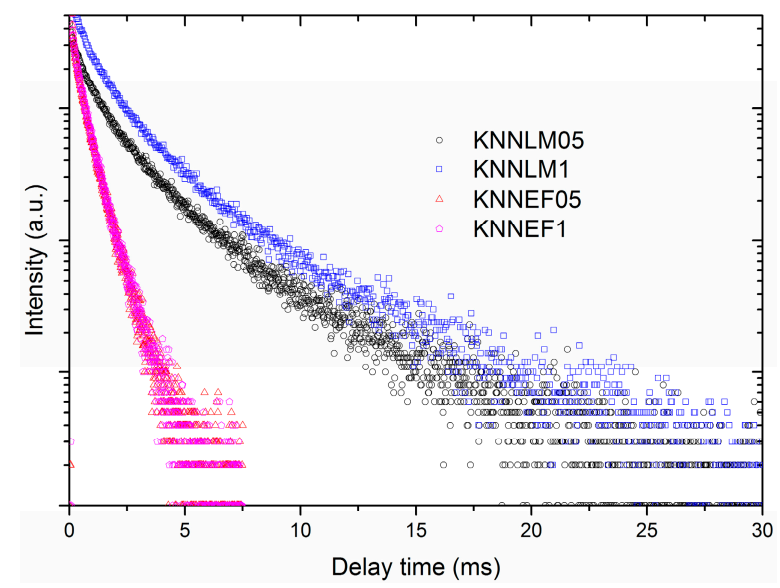

Figure 6. Luminescence decay curves of red emission for La-Mn and Eu-Fe co-doped KNN ceramics.

Additionally, we have calculated the average lifetime for the transitions of ${ }^{2} \mathrm{E}-{ }^{4} \mathrm{~A}_{2}\left(\mathrm{Mn}^{4+}\right)$ and ${ }^{5} \mathrm{D}_{0}-{ }^{7} \mathrm{~F}_{4}\left(\mathrm{Eu}^{3+}\right)$ at different compositions. In the case of $\mathrm{Eu}^{3+}$, the average lifetime was $0.57 \mathrm{~ms}$ regardless of the concentration of $\mathrm{Eu}^{3+}$ and $\mathrm{Fe}^{3+}$. Similar results were obtained for the $\mathrm{Mn}^{4+}$ : the average lifetimes were $2.25 \mathrm{~ms}$ and $2.2 \mathrm{~ms}$ for the samples doped at $0.5 \%$ and $1 \%$, respectively. Large lifetime values may be related with ion transition, which is due to the parity and spin forbidden transition ${ }^{2} \mathrm{E}-{ }^{4} \mathrm{~A}_{2}$ of $\mathrm{Mn}^{4+}$.

It should be noted that the excitation and emission spectra presented above do not show the presence of $\mathrm{Mn}^{2+}$ like in EPR study, for that case another kind of study must be carried out. The presence of $\mathrm{Mn}^{2+}$ can be determined by exciting the characteristic wavelength of the absorption edge (Figure 7a), which ensures the excitation of all the optical centers in the sample [36]. The absorption edge wavelengths for KNNLM05 and KNNLM1 compounds are $360 \mathrm{~nm}$ and $340 \mathrm{~nm}$, respectively. These wavelengths were used to excite the compounds in order to obtain their emission spectra, showed in Figure $7 \mathrm{~b}$, which prove the existence of $\mathrm{Mn}^{2+}$ due to the presence of the band at $580 \mathrm{~nm}$ ascribed to the ${ }^{4} \mathrm{~T}_{1}-{ }^{6} \mathrm{~A}_{1} \mathrm{Mn}^{2+}$ transition [13]. Therefore, the presence of $\mathrm{Mn}^{2+}$ from the weak signal in Figure 7 matches with the results obtained in EPR. These results prove a mix of oxidation states inherent in Mn co-doped compounds, which may induce a conduction behavior at sufficiently high concentration by generation of lattice defects.

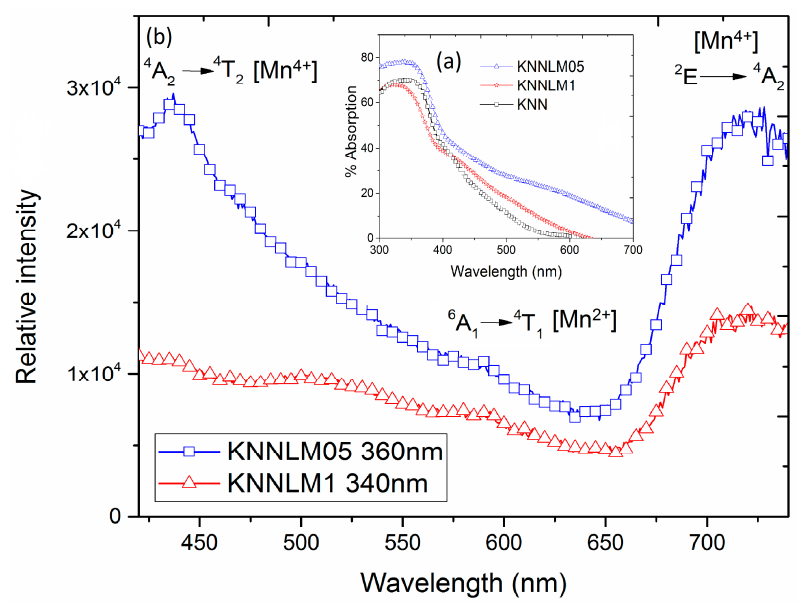

Figure 7. Absorption edge (a) and emission spectra; (b) for KNNLM05 and KNNLM1 compounds. 


\subsection{Electric Characterization}

The ferroelectric loops acquired are presented in Figure 8. Most samples have saturated ferroelectric loops, except for the compounds KNNLM1 and KNNEF05. In the case of KNNLM1, the loop has a rounded shape, attributed to sample conductance. The conductance at room temperature result from manganese mixed valence state, borne out by EPR studies. However, KNNEF05 shows a subcoercive loop, thus, co-doping has caused an increase of the coercive field for this composition, most probably by introducing defect dipoles that stabilize the ferroelectric domains.

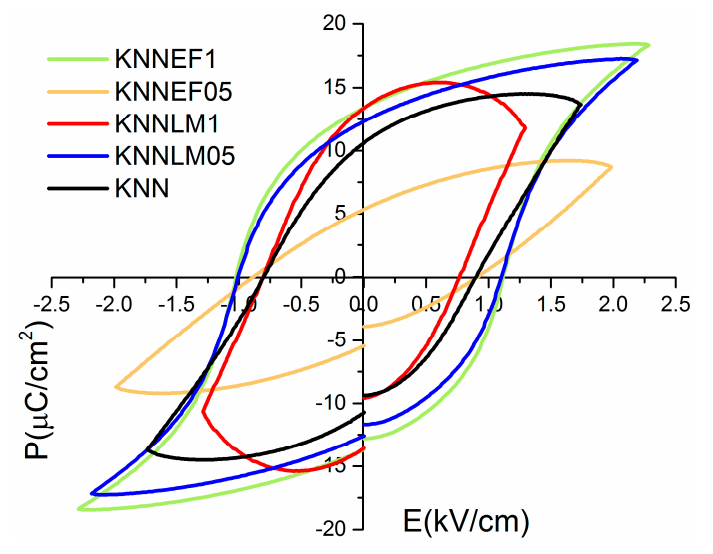

Figure 8. Ferroelectric loops of KNN and its solid solutions.

Table 3 shows the values of the remnant polarization (2Pr) and coercive field (2Ec) for all compounds. Regarding to coercive field, the solid solutions show lower values than un-doped $\mathrm{KNN}$, whereas the value of remnant polarization increases and almost doubles the value observed for KNN. This behavior is similar to previous studies doped solely with transition metals [10-12], making these solid solutions soft ferroelectrics with a greater number of polarizable domains.

Table 3. Remnant polarization $\left(2 \mathrm{P}_{\mathrm{r}}\right)$ and the coercive field $\left(2 \mathrm{E}_{\mathrm{c}}\right)$ for sintered ceramics.

\begin{tabular}{ccc}
\hline Composition & 2P $_{\mathbf{r}}\left(\boldsymbol{\mu C} / \mathbf{c m}^{\mathbf{2}}\right)$ & 2E $_{\mathbf{C}}(\mathbf{k V} / \mathbf{c m})$ \\
\hline KNN & 6.2 & 0.9 \\
KNNLM05 & 12.45 & 1.05 \\
KNNEF1 & 13.54 & 1.07 \\
\hline
\end{tabular}

The exhibited temperature dependence of the dielectric permittivity, measured at $10 \mathrm{kHz}$ for sintered samples, given in Figure 9. The dielectric permittivity graphs show two phase transitions: $\mathrm{T}_{\mathrm{O}-\mathrm{T}}$ at $180-220{ }^{\circ} \mathrm{C}$ and $\mathrm{T}_{\mathrm{T}-\mathrm{C}}\left(\mathrm{T}_{\text {Curie }}\right)$ at $390-430{ }^{\circ} \mathrm{C}$, depending on the compound used. For example, $\mathrm{KNN}$ presents the transitions at $220^{\circ} \mathrm{C}$ and $430{ }^{\circ} \mathrm{C}$, respectively, while KNNLM05 presents them at $195{ }^{\circ} \mathrm{C}$ and close to $420^{\circ} \mathrm{C}$. On the other hand, KNNEF1 shows the transitions at $180{ }^{\circ} \mathrm{C}$ and $390{ }^{\circ} \mathrm{C}$, respectively.

Figure 10 shows the dependence of dielectric losses $(\tan \delta)$ on the temperature measured at $10 \mathrm{kHz}$. Losses are low except for undoped KNN, most probably due to defects caused by the alkaline volatility that are avoided by co-doping [10-12].

The piezoelectric, elastic and dielectric parameters, obtained from the radial resonance of thickness poled thin disks analyzed using an iterative automatic method to obtain material coefficients with all losses [41], are shown in Table 4 . The $d_{33}$ value was also measured and $d_{h}$ was calculated. It is noticeable that $k_{p}$ values were improved for KNNLM05 composition, but if the dopant amount increases, the piezoelectric properties decrease. However, the KNNEF1 compound shows improved piezoelectric properties, but at higher dopant concentrations, values not shown here, the ferroelectric properties are lost. 


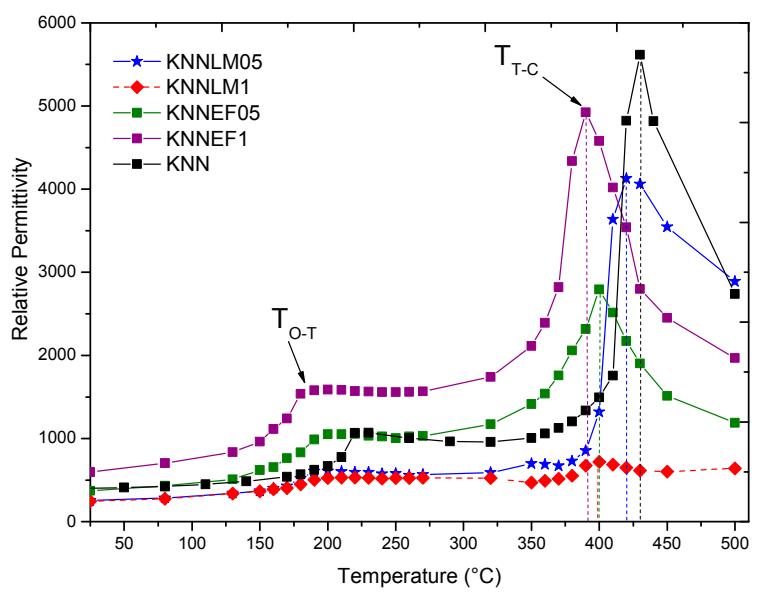

Figure 9. Dielectric permittivity vs. temperature, measured at $10 \mathrm{kHz}$, of KNN and its solids solutions.

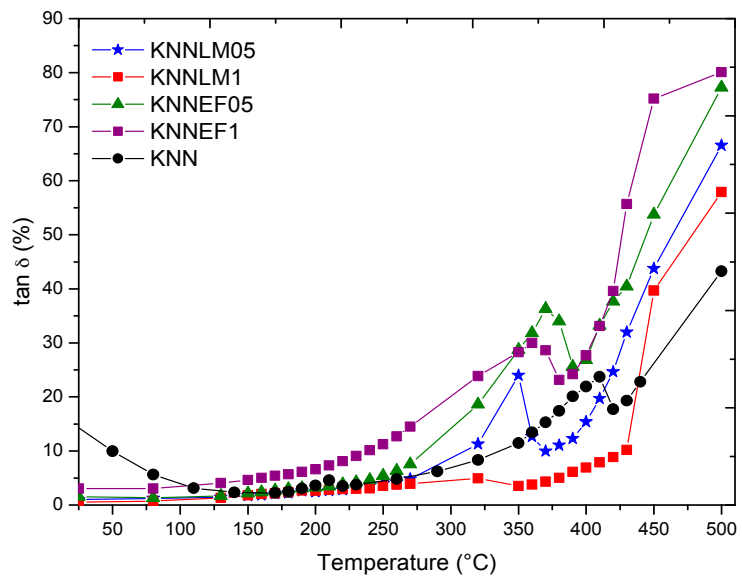

Figure 10. Dielectric loss tangent vs. temperature of KNN and its solid solutions, measured at $10 \mathrm{kHz}$.

Table 4. Piezoelectric, elastic and dielectric coefficients including all losses and other relevant parameters at the radial resonance of a thin disk, thickness poled, and measured at the $\mathrm{d}_{33}$-meter of KNN and its solid solutions.

\begin{tabular}{cccccc}
\hline Sample & KNN & KNNLM05 & KNNLM1 & KNNEF05 & KNNEF1 \\
\hline$\delta\left(\mathrm{g} / \mathrm{cm}^{3}\right)$ & 4.34 & 4.4 & 4.27 & 4.375 & 4.415 \\
$\mathrm{R}^{2}$ & 0.9973 & 0.9978 & 0.9992 & 0.9982 & 0.9809 \\
$\mathrm{~Np}(\mathrm{kHz} \cdot \mathrm{mm})$ & 3357 & 2997 & 2353 & 2874 & 3378 \\
$\mathrm{kp}(\%)$ & 34.1 & 26,7 & 16.8 & 23.9 & 31.9 \\
$\mathrm{k}_{31}(\%)$ & 20.0 & 13.7 & 12.0 & 14.2 & 18.7 \\
Poisson's ratio & $0.311+0.0003 \mathrm{i}$ & $0.475+0.0001 \mathrm{i}$ & - & $0.295-0.0001 \mathrm{i}$ & $0.312+0.0001 \mathrm{i}$ \\
$\mathrm{c}_{11 \mathrm{p}}{ }^{\mathrm{E}}\left(10^{10} \mathrm{~N} \cdot \mathrm{m}^{-2}\right)$ & $11.43+0.04 \mathrm{i}$ & $8.42+0.02 \mathrm{i}$ & $7.03+0.04 \mathrm{i}$ & $8.52+0.04 \mathrm{i}$ & $11.76+0.16 \mathrm{i}$ \\
$\mathrm{s}_{11}{ }^{\mathrm{E}}\left(10^{-12} \mathrm{~m}^{2} \cdot \mathrm{N}^{-1}\right)$ & $9.69-0.03 \mathrm{i}$ & $15.33-0.04 \mathrm{i}$ & $14.23-0.07 \mathrm{i}$ & $12.85-0.05 \mathrm{i}$ & $9.42-0.13 \mathrm{i}$ \\
$\mathrm{s}_{12}{ }^{\mathrm{E}}\left(10^{-12} \mathrm{~m}^{2} \cdot \mathrm{N}^{-1}\right)$ & $-3.02+0.01 \mathrm{i}$ & $-7.28+0.02 \mathrm{i}$ & - & $-3.79+0.02 \mathrm{i}$ & $-2.94+0.04 \mathrm{i}$ \\
$\mathrm{d}_{31}\left(10^{-12} \mathrm{C} \cdot \mathrm{N}^{-1}\right)$ & $-28.99+0.27 \mathrm{i}$ & $-25.55+0.19 \mathrm{i}$ & $-19.20+0.36 \mathrm{i}$ & $-30.09+0.44 \mathrm{i}$ & $-40.13+1.56 \mathrm{i}$ \\
$\varepsilon_{33}{ }^{\mathrm{T}}(\mathrm{real})$ & 244.86 & 257.38 & 203.14 & 395.23 & 552.15 \\
$\tan \delta$ & 0.015 & 0.012 & 0.030 & 0.021 & 0.037 \\
$\mathrm{~s}_{66}{ }^{\mathrm{E}}\left(10^{-12} \mathrm{~m}^{2} \cdot \mathrm{N}^{-1}\right)$ & $25.41-0.09 \mathrm{i}$ & $45.23-0.13 \mathrm{i}$ & $27.72-0.14 \mathrm{i}$ & $33.26-0.14 \mathrm{i}$ & $24.71-0.33 \mathrm{i}$ \\
$\mathrm{c}_{11} \mathrm{D}\left(10^{10} \mathrm{~N} \cdot \mathrm{m}^{-2}\right)$ & $12.41+0.04 \mathrm{i}$ & $8.90+0.03 \mathrm{i}$ & $7.13+0.04 \mathrm{i}$ & $8.86+0.04 \mathrm{i}$ & $12.64+0.15 \mathrm{i}$ \\
$\mathrm{s}_{11} \mathrm{D}\left(10^{-12} \mathrm{~m}^{2} \cdot \mathrm{N}^{-1}\right)$ & $9.30-0.03 \mathrm{i}$ & $15.05-0.04 \mathrm{i}$ & $14.02-0.07 \mathrm{i}$ & $12.59-0.0520 \mathrm{i}$ & $9.09-0.11 \mathrm{i}$ \\
$\mathrm{s}_{12} \mathrm{D}\left(10^{-12} \mathrm{~m}^{2} \cdot \mathrm{N}^{-1}\right)$ & $-3.40+0.01 \mathrm{i}$ & $-7.60+0.02 \mathrm{i}$ & - & $-4.04+0.02 \mathrm{i}$ & $-3.27+0.05 \mathrm{i}$ \\
$\mathrm{g}_{31}\left(10^{-3} \mathrm{~m} \cdot \mathrm{V} \cdot \mathrm{N}^{-1}\right)$ & $-13.37-0.08 \mathrm{i}$ & $-11.21-0.06 \mathrm{i}$ & $-10.67-0.14 \mathrm{i}$ & $-8.60-0.05 \mathrm{i}$ & $-8.21+0.01 \mathrm{i}$ \\
$\mathrm{d}_{33}\left(10^{-12} \mathrm{C} / \mathrm{N}\right)$ & 98 & 120 & 94 & 105 & 116 \\
$\mathrm{~d}_{\mathrm{h}}\left(10^{-12} \mathrm{C} / \mathrm{N}\right)$ & 40 & 69 & 56 & 45 & 36 \\
\hline
\end{tabular}


Figure 11 shows an example of the planar resonance spectra used for the calculation of the coefficients in Table 4. Instead of the usual plot of impedance modulus and phase the plot was made using the resistance ( $R=$ real part of the impedance) and conductance $(G=$ real part of the admittance) peaks, since these are used in the calculation. It is noticeable the high agreement, also given by the regression factor $\left(R^{2}\right)$ (see Table 4 ), of the reproduced spectra (doted lines) to the measured one (symbols), which indicates the precision of the obtained materials parameters and the losses.

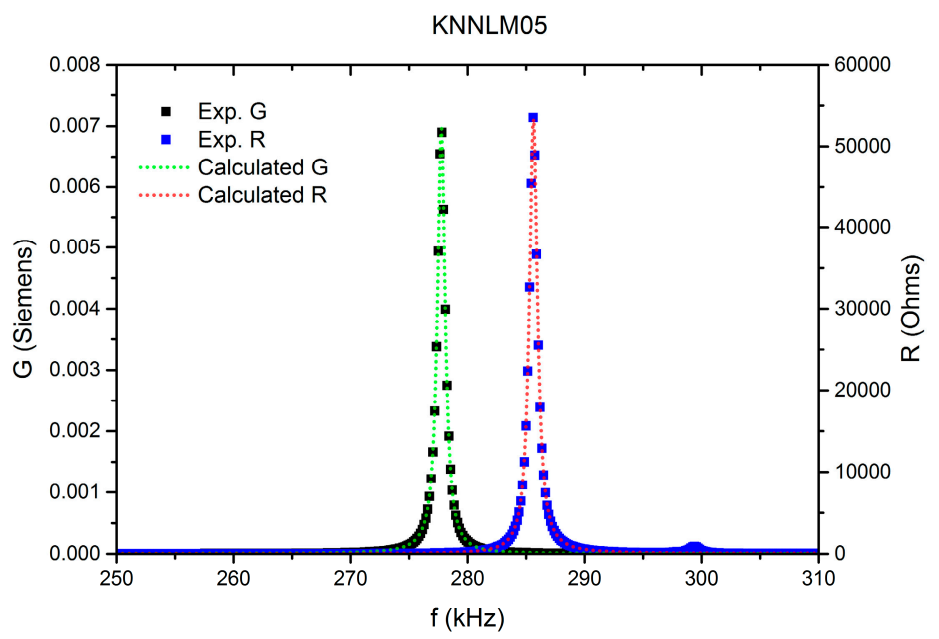

Figure 11. Planar resonance spectra for KNNLM05.

The best overall performances were obtained for KNNLM05 and KNNEF1 compounds. The slight decrease in some of the piezoelectric parameters $(\mathrm{kp})$ for the compounds doped with manganese compared with the undoped KNN can be explained by the mixed valence states found by EPR studies. These mixed oxidation states produce a.c. conduction due to defects in the crystalline lattice of the composition with higher co-doping that result in duplicated dielectric $\tan \delta$ in KNNLM1 with respect to undoped KNN. This effects are compensated with the better elastic properties of the co-doped ceramics, resulting from a fine grain dense microstructure, revealed by the higher modulus of the compliances $\left(\mathrm{s}_{\mathrm{ij}}^{\mathrm{E}, \mathrm{D}}\right)$ and lower the stiffness $\left(\mathrm{c}_{11 \mathrm{p}} \mathrm{E}, \mathrm{D}\right)$, while keeping similarly low mechanical losses, and ultimately in an improvement for some other parameters $\left(\mathrm{d}_{33}\right.$ and $\left.\mathrm{d}_{\mathrm{h}}\right)$.

However, in the compound co-doped with Eu-Fe the piezoelectric parameters decrease first in KNNEF05 and increase again in agreement with the doping effect of $\mathrm{Fe}^{3+}$ ions previously observed in the literature [14] and similar effects than in KNNLM concerning the elastic properties.

The highest values in the co-doped ceramics for $d_{33}(120 \mathrm{pC} / \mathrm{N})$ and $d_{h}(69 \mathrm{pC} / \mathrm{N})$ were obtained for KNNLM05 and for $k_{p}(31.1 \%)$ in KNNEF1 compounds, respectively. As it is well known, $d_{h}$ is typically the most important parameter for underwater sound transducers, commonly manufactured using lead titanate ceramic material. Since KNNLM05 and KNNLM1 show the best $d_{h}$ values, it proves to be suitable for sonar applications [42-44].

\section{Materials and Methods}

For the synthesis of $\mathrm{KNN}$ and the solid solutions $\left(\mathrm{K}_{0.5} \mathrm{Na}_{0.5}\right)_{1-(4 x / 5)} \mathrm{La}_{(4 x / 5)} \mathrm{Nb}_{1-x} \mathrm{Mn}_{4.5 x / 5} \mathrm{O}_{3}$ and $\left(\mathrm{K}_{0.5} \mathrm{Na}_{0.5}\right)_{1-\mathrm{x}} \mathrm{Eu}_{\mathrm{x}} \mathrm{Nb}_{1-\mathrm{x}} \mathrm{Fe}_{\mathrm{x}} \mathrm{O}_{3}$ (with $\mathrm{x}=0.005$ and 0.01 ), the following raw materials were used: $\mathrm{Nb}_{2} \mathrm{O}_{5}$ (99.9\% Sigma-Aldrich, St. Louis, MO, USA), $\mathrm{K}_{2} \mathrm{CO}_{3}$ ( $99.8 \%$ Mallinckrodt, Phillipsburg, KY, USA), $\mathrm{Na}_{2} \mathrm{CO}_{3}$ (99.8\% J.T. Baker, Xalostoc, Mexico), $\mathrm{La}(\mathrm{OH})_{3}$ (99.9\% Sigma-Aldrich), $\mathrm{Fe}_{2} \mathrm{O}_{3}$ (99.77\% Fisher Scientific, Fair Lawn, NJ, USA), $\mathrm{Eu}_{2} \mathrm{O}_{3}$ (99.9\% Sigma-Aldrich) and $\mathrm{MnO}_{2}(98 \%$ Alfa Aesar, Ward Hill, MA, USA).

First, the carbonates and oxides were dried at $200{ }^{\circ} \mathrm{C}$ during $4 \mathrm{~h}$ before weighting. Then, stoichiometric amounts of the precursors were mixed in an agate mortar using acetone as dispersant. 
The mixture was calcined at $800{ }^{\circ} \mathrm{C}$ for $1 \mathrm{~h}$, milled again in the agate mortar and heated at $950-1000{ }^{\circ} \mathrm{C}$ during $2 \mathrm{~h}$. The powder was milled in a planetary ball mill using zirconia balls at $200 \mathrm{RPM} \mathrm{for} 10 \mathrm{~h}$ with ethanol as dispersant. Meanwhile, solid solutions with the highest dopant amount (solubility limit) were synthetized at $1000{ }^{\circ} \mathrm{C}$ for $8 \mathrm{~h}$.

The powders were pressed into pellets of $13 \mathrm{~mm}$ diameter and $2 \mathrm{~mm}$ thickness at $45 \mathrm{MPa}$. The samples were conventionally sintered at temperatures between $1105^{\circ} \mathrm{C}$ and $1150{ }^{\circ} \mathrm{C}$ for $2 \mathrm{~h}$. Bulk densities of sintered ceramics was measured by Archimedes method.

All samples were characterized by $X$-ray diffraction with $\mathrm{Cu}-\mathrm{K} \alpha$ radiation $(\lambda=0.15418 \mathrm{~nm}$, Bruker D8 Advance with a 0.0083 step size and 2 s integration time, Karlsruhe, Germany) and Rietveld refinements were carried out to determine the composition influence in the structure using TOPAS software (Bruker, Brisbane, Australia) [45]. The microstructures of sintered pellets were examined with a Scanning Electron Microscope (SEM, JEOL 7600F, Tokyo, Japan). Electron Paramagnetic Resonance (EPR) was carried out in an Electron Paramagnetic Resonance Spectrometer (JEOL JES-TE300, Tokyo, Japan), using a cylindrical cavity with the $\mathrm{TE}_{011}$ mode, operated at $100 \mathrm{kHz}$ in $X$ modulated band. The measurements were performed at room temperature in quartz tubes to determine the valence of paramagnetic centers in the obtained compounds.

The excitation and emission spectra of the sintered pellets were carried out in a spectrometer (Edinburgh F900, Edinburg Instrument, Livingston, UK), whereas the absorption edge was acquired only for the compounds co-doped with La-Mn, using a spectrophotometer (Cary 5000, Agilent Technologies, San Jose, CA, USA).

For the luminescence decay curves of red emission. The average lifetime is defined as

$$
\tau_{\mathrm{m}}=\int_{0}^{\infty} \mathrm{tI}(\mathrm{t}) / \int_{0}^{\infty} \mathrm{I}(\mathrm{t})
$$

where $\mathrm{I}(\mathrm{t})$ is the intensity as a function of the time. This can be a also written as

$$
\tau_{\mathrm{m}}=\frac{\int_{0}^{\infty} \mathrm{tI}(\mathrm{t})}{\int_{0}^{\infty} \mathrm{I}(\mathrm{t})}=\sum_{\mathrm{i}} \mathrm{B}_{\mathrm{i}} \tau_{\mathrm{i}}^{2} / \sum_{\mathrm{i}} \mathrm{B}_{\mathrm{i}} \tau_{\mathrm{i}}
$$

We here determined the lifetime by fitting the experimental curves to the first two terms in the expression shown above.

In order to determine changes in dielectric and piezoelectric properties, sintered pellets were polished down to $1 \mathrm{~mm}$ of thickness, silver paste was applied and then annealed at $100{ }^{\circ} \mathrm{C}$ for $3 \mathrm{~h}$. Dielectric and piezoelectric properties were measured using a Precision Impedance Analyzer (Agilent 4295A, San Jose, CA, USA).

The hysteresis loops (P-E) were acquired on a ferroelectric tester (Radiant RT66B work station, Radiant Technologies Inc., Alpharetta, CA, USA, at $100 \mathrm{~Hz}$ using an external $4 \mathrm{kV}$ power supply source). For piezoelectric characterization, the samples were poled under $1-1.5 \mathrm{kV} \cdot \mathrm{mm}^{-1} \mathrm{dc}$ electric field at $175{ }^{\circ} \mathrm{C}$ for $30 \mathrm{~min}$ in a silicon oil bath. All measurements were performed after $24 \mathrm{~h}$ of poling process. The piezoelectric parameter $\mathrm{d}_{33}$ was measured with a $\mathrm{d}_{33}$ piezometer system (PM300-PIEZOTEST). The $d_{31}$ parameter, as well as the electrochemical coupling factors $k_{P}$ and $k_{31}$, and $g_{31}$ parameter, together with elastic constants and permittivity at the resonance frequency, were calculated using the resonance method by an automatic iterative analysis method of the complex impedance at the radial mode of thin disks, thickness poled [41].

\section{Conclusions}

$\left(\mathrm{K}_{0.5} \mathrm{Na}_{0.5}\right)_{1-(4 \mathrm{x} / 5)} \mathrm{La}_{(4 \mathrm{x} / 5)} \mathrm{Nb}_{1-\mathrm{x}} \mathrm{Mn}_{4.5 \mathrm{x} / 5} \mathrm{O}_{3}$ and $\left(\mathrm{K}_{0.5} \mathrm{Na}_{0.5}\right)_{1-\mathrm{x}} \mathrm{Eu}_{\mathrm{x}} \mathrm{Nb}_{1-\mathrm{x}} \mathrm{Fe}_{\mathrm{x}} \mathrm{O}_{3}$ solid solutions (with $\mathrm{x}=0.005$ and 0.01 ) were successfully synthesized by solid-state method and sintered to obtain dense ceramics. Pure perovskite phase was achieved for all compositions as observed by X-ray diffraction. The Rietveld refinements show shifts in lattice parameters and result in a change of crystal symmetry, from orthorhombic to tetragonal, as the amount of co-doping increases. 
EPR and optical measurements confirm the oxidation state of the Mn ions: the wide band centered at $720 \mathrm{~nm}$, ascribed to the ${ }^{2} \mathrm{E}-{ }^{4} \mathrm{~A}_{2}$ transition of $\mathrm{Mn}^{4+}$ of the emission spectra, and the presence of the band at $580 \mathrm{~nm}$ ascribed to the ${ }^{4} \mathrm{~T}_{1}-{ }^{6} \mathrm{~A}_{1}$ transition, due to the $\mathrm{Mn}^{2+}$ from excitation at the absorption edge. The mixed oxidation states of manganese explain the conductive behavior at high dopant concentrations, resulting in leaky hysteresis loops and reduction of the piezoelectric coefficients.

EPR results and the ${ }^{4} \mathrm{~T}_{1}-{ }^{6} \mathrm{~A}_{1}$ transition at $705 \mathrm{~nm}$ ascribed to $\mathrm{Fe}^{3+}$ of the emission spectra; confirm the oxidation state of the $\mathrm{Fe}^{3+}$ ions. The change in the relative intensity of the transitions $\mathrm{I}\left({ }^{7} \mathrm{~F}_{2}\right) / \mathrm{I}\left({ }^{7} \mathrm{~F}_{1}\right)$ of samples of the solid solution with $\mathrm{Eu}-\mathrm{Fe}$ is an evidence of a higher distortion in the crystal structure due to the dopant content, which is directly related with the dielectric, ferroelectric and piezoelectric properties of the Eu-Fe solid solution.

Generation of optical properties, while piezoelectric properties are kept similar to pure KNN), and higher for hydrostatic applications in KNNLM, were exhibited by the La-Mn co-doped samples especially at $0.5 \%$ mol (KNNLM05). Meanwhile for Eu-Fe co-doped samples, the best electromechanical properties were obtained at $1 \mathrm{~mol} \%$ (KNNEF1).

Acknowledgments: Jesús-Alejandro Peña-Jiménez is grateful to CONACyT-México for his PhD scholarship. María-Elena Villafuerte-Castrejón thanks the support for the sabbatical year on the ICMM-CSIC (Madrid, Spain) of PASPA-DGAPA, UNAM and CONACyT-México and also kindly acknowledges the financial support under project IN116610-3, PAPIIT-UNAM. Also, Federico González gives special thanks to CONACyT for providing financial support through Project 154962. We want to thank to Virginia Gomez Vidal for EPR measurements acquisition, as well as to Omar Novelo for SEM images acquisition and Adriana Tejeda Cruz for her technical assistance.

Author Contributions: Jesús-Alejandro Peña-Jiménez and María-Elena Villafuerte-Castrejón designed the work, discussed the results and wrote the manuscript; Jesús-Alejandro Peña-Jiménez made the studied materials, performed the measurements and analysed all experimental results; José-Manuel Hernández-Alcántara, Enrique Camarillo, Héctor Murrieta-Sánchez conceived and designed the optical experiments; Federico González, Rigoberto López-Juárez and Lorena Pardo analysed and discussed the optical and electrical measurements.

Conflicts of Interest: The authors declare no conflict of interest.

\section{References}

1. Jaffe, B.; Cook, W.R.; Jaffe, H. Piezoelectric Ceramics; Academic Press: London, UK; New York, NY, USA, 1971; pp. 7-48 and pp. 185-210.

2. Wang, $\mathrm{K}$.; Li, J.-F. Analysis of crystallographic evolution in $(\mathrm{Na}, \mathrm{K}) \mathrm{NbO}_{3}$-based lead-free piezoceramics by X-ray diffraction. Appl. Phys. Lett. 2007, 91, 262902. [CrossRef]

3. Ringgard, E.; Wurlitzer, T. Lead-free piezoceramics based on alkali niobates. J. Eur. Ceram. Soc. 2005, 25, 1701-1706. [CrossRef]

4. Villafuerte-Castrejón, M.E.; Morán, E.; Reyes-Montero, A.; Vivar-Ocampo, R.; Peña-Jiménez, J.-A.; Rea-López, S.-O.; Pardo, L. Towards Lead-Free Piezoceramics: Facing a Synthesis Challenge. Materials 2016, 9, 21. [CrossRef]

5. Saito, Y.; Takko, H.; Tani, T.; Nonoyama, T.; Tkatori, K.; Homma, T.; Nagaya, T.; Nakamura, M. Lead-free piezoceramics. Nature 2004, 42, 84-87. [CrossRef] [PubMed]

6. Ahtee, M.; Glazer, A.M. Lattice parameters and tilted octahedral in sodium-potasium niobate solid solutions. Acta Cryst. A 1976, 32, 434-446. [CrossRef]

7. Katz, L.; Megaw, H.D. The structure of potassium niobate at room temperature: The solution of a pseudosymmetric structure by Fourier methods. Acta Cryst. 1967, 22, 639-648. [CrossRef]

8. Hewat, A.W. Cubic-tetragonal-orthorhombic-rhombohedral ferroelectric transitions in perovskite potassium niobate: Neutron powder profile refinement of the structures. J. Phys. C Solid State Phys. 1973, 6, 2559-2572. [CrossRef]

9. López-Juárez, R.; González, F.; Villafuerte-Castrejón, M.E. Lead-free ferroelectric ceramics with perovskite structure. In Ferroelectrics—Materials Aspects; Lallart, M., Ed.; In Tech: Rijeka, Croatia, 2011; pp. 305-330.

10. Lee, S.Y.; Ahn, C.W.; Ullah, A.; Seog, H.J.; Kim, J.S.; Bae, S.H.; Kim, I.W. Effect of Mn substitution on ferroelectric and leakage current characteristics of lead-free $\left(\mathrm{K}_{0.5} \mathrm{Na}_{0.5}\right)\left(\mathrm{Mn}_{\mathrm{x}} \mathrm{Nb}_{1-\mathrm{x}}\right) \mathrm{O}_{3}$ thin films. Curr. Appl. Phys. 2011, 11, S266-S269. [CrossRef] 
11. Kim, B.H.; Yang, S.A.; Kang, S.W.; Choi, G.P.; Cho, S.Y.; Han, J.K.; Lee, G.J.; Lee, M.K.; Kim, I.W.; Bu, S.D. Change of electrical properties of $\left(\mathrm{K}_{0.5} \mathrm{Na}_{0.5}\right)\left(\mathrm{Mn}_{0.005} \mathrm{Nb}_{0.995}\right) \mathrm{O}_{3}$ thin films induced by gamma-ray irradiation. Curr. Appl. Phys. 2016, 16, S39-S44. [CrossRef]

12. Lin, D.; Li, Z.; Zhang, S.; Xu, Z.; Yao, X. Influence of $\mathrm{MnO}_{2}$ doping on the dielectric and piezoelectric properties and the domain structure in $\left(\mathrm{K}_{0.5} \mathrm{Na}_{0.5}\right) \mathrm{NbO}_{3}$ single crystals. J. Am. Ceram. Soc. 2010, 93, 941-944. [CrossRef]

13. Dan, H.K.; Zhou, D.; Wang, R.; Jiao, Q.; Yang, Z.; Song, Z.; Yu, X.; Qui, J. Effect of $\mathrm{Mn}^{2+}$ ions on the enhancement upconversion emission and energy transfer of $\mathrm{Mn}^{2+} / \mathrm{Tb}^{3+} / \mathrm{Yb}^{3+}$ tri-doped transparent glass-ceramics. Mater. Lett. 2015, 150, 76-80. [CrossRef]

14. Yang, W.; Zhou, Z.; Yang, B.; Zhang, R.; Wang, Z.; Chen, H.; Jiang, Y. Structure and piezoelectric properties of Fe-doped potassium sodium niobate tantalate lead-free ceramics. J. Am. Ceram. Soc. 2011, 94, 2489-2493. [CrossRef]

15. Abdulrahem, Y.M.; Gentile, A.L.; Stafsudd, O.M. The Effect of iron as a dopant on the dielectric properties of ferroelectric potassium tantalate niobate $\left(\mathrm{KTa}_{x} \mathrm{Nb}_{1-\mathrm{x}} \mathrm{O}_{3}\right)$. J. Appl. Phys. 2006, 100, 104111. [CrossRef]

16. Fang, T.-H.; Hsiao, Y.-J.; Chang, Y.-S.; Chang, Y.-H. Photoluminescent characterization of $\mathrm{KNbO}_{3}: \mathrm{Eu}^{3+}$. Mater. Chem. Phys. 2006, 100, 418-422. [CrossRef]

17. Wu, X.; Lau, C.M.; Kwok, K.W. Effect of phase transition on photo luminescence of Er-doped KNN ceramics. J. Luminescence 2014, 155, 343-350. [CrossRef]

18. Wang, J.; Song, H.; Kong, X.; Peng, H.; Sun, B.; Chen, B.; Zhang, J.; Xu, W.; Xia, H. Fluorescence properties of trivalent europium doped in various niobate codoped glasses. J. Appl. Phys. 2003, 93, 1482-1486. [CrossRef]

19. Sun, H.; Peng, D.; Wang, X.; Tang, M.; Zhang, Q.; Yao, X. Green and red emission for $\left(\mathrm{K}_{0.5} \mathrm{Na}_{0.5}\right) \mathrm{NbO}_{3}: \mathrm{Pr}$ ceramics. J. Appl. Phys. 2012, 111, 046102. [CrossRef]

20. Zhao, Y.; Ge, Y.; Zhang, X.; Zhao, Y.; Zhou, H.; Li, J.; Jin, H.B. Comprehensive investigation of $\mathrm{Er}_{2} \mathrm{O}_{3}$ doped $(\mathrm{Li}, \mathrm{K}, \mathrm{Na}) \mathrm{NbO}_{3}$ ceramics rendering potential application in novel multifunctional devices. J. Alloys Compd. 2016, 683, 171-177. [CrossRef]

21. Wei, Y.; Wu, Z.; Jia, Y.; Wu, J.; Shen, Y.; Luo, H. Dual-enhancement of ferro-/piezoelectric and photoluminescent performance in $\mathrm{Pr}^{3+}$ doped $\left(\mathrm{K}_{0.5} \mathrm{Na}_{0.5}\right) \mathrm{NbO}_{3}$ lead-free ceramics. Appl. Phys. Lett. 2014, 105, 042902. [CrossRef]

22. Tian, X.; Wu, Z.; Jia, Y.; Chen, J.; Zheng, R.K.; Zhang, Y.; Luo, H. Remanent-polarization-induced enhancement of photoluminescence in $\mathrm{Pr}^{3+}$-doped lead-free ferroelectric $\left(\mathrm{Bi}_{0.5} \mathrm{Na}_{0.5}\right) \mathrm{TiO}_{3}$ ceramic. Appl. Phys. Lett. 2013, 102, 042907. [CrossRef]

23. Jiang, X.P.; Chen, Y.; Lam, K.H.; Choy, S.H.; Wang, J. Effect of MnO doping on properties of $0.97 \mathrm{~K}_{0.5} \mathrm{Na}_{0.5} \mathrm{NbO}_{3}-0.03\left(\mathrm{Bi}_{0.5} \mathrm{~K}_{0.5}\right) \mathrm{TiO}_{3}$ piezoelectric ceramic. J. Allows Compd. 2010, 506, 323-326. [CrossRef]

24. Malic, B.; Bernard, J.; Holc, J.; Jenko, D.; Kosec, M. Alkaline-earth doping in (K,Na) $\mathrm{NbO}_{3}$ based piezoceramics. J. Eur. Ceram. Soc. 2005, 25, 2707-2711. [CrossRef]

25. Ishizawa, N.; Wang, J.; Sakakura, T.; Inagaki, Y.; Kakimoto, K. Structural evolution of $\mathrm{Na}_{0.5} \mathrm{~K}_{0.5} \mathrm{NbO}_{3}$ at high temperatures. J. Solid State Chem. 2010, 183, 2731-2738. [CrossRef]

26. Yan, M.F. Microstructural control in the processing of electronic ceramics. Mater. Sci. Eng. 1981, 48, 53-72. [CrossRef]

27. George, D. Watkins, Electron spin resonance of $\mathrm{Mn}^{2+}$ in alkali chlorides: Association with vacancies and impurities. Phys. Rev. 1958, 113, 79-89.

28. Singh, V.; Sivariamaiah, G.; Rao, J.L.; Kim, S.H. Optical and EPR properties of $\mathrm{BaAl}_{12} \mathrm{O}_{19}: \mathrm{Eu}^{2+}, \mathrm{Mn}^{2+}$ phosphor prepared by facile solution combustion approach. J. Luminescence 2015, 157, 74-81. [CrossRef]

29. Wang, X.F.; Xu, J.-J.; Chen, H.-Y. A new electrochemiluminescence emission of $\mathrm{Mn}^{2+}$-doped ZnS nanocrystals in aqueous solution. J. Phys. Chem. C 2008, 112, 17581-17585. [CrossRef]

30. Kripal, R.; Govind, H.; Bajpai, M.; Maurya, M. EPR and optical study of $\mathrm{Mn}^{2+}$ doped ammonium tartrate single crystals. Spectrochim. Acta Part A 2008, 71, 1302-1306. [CrossRef] [PubMed]

31. Kripal, R.; Maurya, M. Characterization of $\mathrm{Mn}^{2+}$ doped tetramethylammoniumtetrachlorozincate single crystal using EPR and Optical absorption. Mater. Chem. Phys. 2008, 108, 257-262. [CrossRef]

32. Celayn, Ü.; Tapramaz, R. The EPR study of $\mathrm{Mn}^{2+}$ ion doped DADT single crystal produced under high pressure and temperature. Spectrochim. Acta Part A Mol. Biomol. Spectrosc. 2016, 152, 680-684. [CrossRef] [PubMed] 
33. Cheng, Y.; Wang, M.; Wang, J.; Wu, M.; Wang, C. A high color purity red emitting phosphor CaYAlO $4: \mathrm{Mn}^{4+}$ for LEDs. J. Solid State Light. 2014, 1. [CrossRef]

34. Stoyanova, R.; Zhecheva, E.; Vassilev, S. $\mathrm{Mn}^{4+}$ environment in layered $\mathrm{Li}\left(\mathrm{Mg}_{0.5-\mathrm{x}} \mathrm{Ni}_{\mathrm{x}} \mathrm{Mn}_{0.5}\right) \mathrm{O}_{2}$ oxides monitored by EPR spectroscopy. J. Solid State Chem. 2006, 179, 378-388. [CrossRef]

35. Stoyanova, R.; Gorova, M.; Zhecheva, E. EPR of $\mathrm{Mn}^{4+}$ in spinels $\mathrm{Li}_{1+\mathrm{x}} \mathrm{Mn}_{2-\mathrm{x}} \mathrm{O}_{4}$ with $0<x<0.1$. J. Phys. Chem. Solids 2000, 61, 609-614.

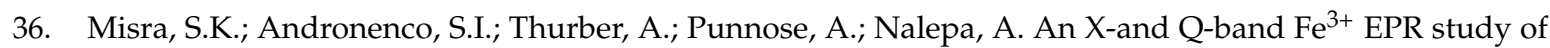
nanoparticles of magnetic semiconductor $\mathrm{Zn}_{1-\mathrm{x}} \mathrm{Fe}_{\mathrm{x}} \mathrm{O}$. J. Magn. Magn. Mater. 2014, 363, 82-87. [CrossRef]

37. Vercamer, V.; Lelong, G.; Hijiya, H.; Kondo, Y.; Galoisy, L.; Calas, G. Diluted Fe ${ }^{3+}$ in silicate glasses: Structural effects of Fe-redox state and matrix composition. An optical absorption and X-band/Q-band EPR study. J. Non-Crystaline Solids 2015, 428, 138-145. [CrossRef]

38. Devaraja, P.B.; Avadhani, D.N.; Nagabhushana, H.; Prashantha, S.C.; Sharma, S.C.; Nagabhushana, B.M.; Nagaswarupa, H.P.; Daruka Prasad, B. Luminescence properties of $\mathrm{MgO}: \mathrm{Fe}^{3+}$ nanopowders for WLEDs under NUV excitation prepared via propellant combustion route. J. Radiat. Res. Appl. Sci. 2015, 8, 362-373. [CrossRef]

39. Zhydachevskii, Y.; Suchocki, A.; Pajaczkowska, A.; Kloss, A.; Szysiak, A.; Reszka, A. Spectroscopic properties of $\mathrm{Mn}^{4+}$ ions in $\mathrm{SrLaAlO}_{4}$. Opt. Mater. 2015, 35, 1664-1668. [CrossRef]

40. Chen, R. Apparent stretched-exponential luminescence decay in crystalline solids. J. Luminescence 2003, 102-103, 510-518. [CrossRef]

41. Alemany, C.; Gonzalez, A.M.; Pardo, L.; Jimenez, B.; Carmona, F.; Mendiola, J. Automatic determination of complex constants of piezoelectric lossy materials in the radial mode. J. Phys. D Appl. Phys. 1995, 28, 945-956. [CrossRef]

42. Haertling, G.H. Ferroelectric ceramics: History and technology. J. Am. Ceram. Soc. 1999, 82, 797-818. [CrossRef]

43. Panda, P.K. Review: Environmental friendly lead-free piezoelectric materials. J. Mater. Sci. 2009, 44, 5049-5062. [CrossRef]

44. Rosen, C.Z.; Hiremath, B.V.; Newnham, R. Piezoelectricity; American Institute of Physics: New York, NY, USA, 1992; p. 205.

45. Bruker AXS, (2005) TOPAS V4.1: General Profile and Structure Analysis Software for Powder Diffraction Data-User's Manual, Bruker AXS, Brisbane, Australia, TOPAS. Available online: http://www.topasacademic.net (accessed on 14 July 2016).

(C) 2016 by the authors; licensee MDPI, Basel, Switzerland. This article is an open access article distributed under the terms and conditions of the Creative Commons Attribution (CC-BY) license (http:/ / creativecommons.org/licenses/by/4.0/). 